\title{
Correction to: Numerical investigation of electro-thermo-convection in a square enclosure with incorporated hot solid body
}

\author{
Walid Hassen ${ }^{2} \cdot$ Lioua Kolsi $^{3} \cdot$ Kaouther Ghachem ${ }^{1} \cdot$ Mohamed A. Almeshaal $^{4} \cdot$ Chemseddine Maatki $^{4}$. \\ Mohamed Naceur Borjini ${ }^{2}$
}

Published online: 10 July 2020

๑) Akadémiai Kiadó, Budapest, Hungary 2020

\section{Correction to: Journal of Thermal Analysis and Calorimetry https://doi.org/10.1007/s10973-020-09821-6}

In the original publication of the article, under the section 'Affiliation' number 1, the sentence that read as "Department of Industrial Engineering and Systems, College of Engineering, Princess Noura bint Abdu Rahman University, Riyadh, 84428, Saudi Arabia" should read as "Department of Industrial Engineering and Systems, College of Engineering, Princess Nourah bint Abdulrahman University, Riyadh, 84428, Saudi Arabia".

The original article can be found online at https://doi.org/10.1007/ s10973-020-09821-6.

Lioua Kolsi

1.kolsi@uoh.edu.sa

Walid Hassen

hassen.walid@gmail.com

Kaouther Ghachem

kgmaatki@pnu.edu.sa

Mohamed A. Almeshaal

maalmeshaal@imamu.edu.sa

1 Department of Industrial Engineering and Systems, College of Engineering, Princess Nourah bint Abdulrahman University, Riyadh 84428, Saudi Arabia

2 Laboratory of Metrology and Energy Systems, University of Monastir, Monastir, Tunisia

3 Mechanical Engineering Department, College of Engineering, Ha'il University, Ha'il, Saudi Arabia

4 Department of Mechanical Engineering, College of Engineering, Al Imam Mohammad Ibn Saud Islamic University, Riyadh, Saudi Arabia
Publisher's Note Springer Nature remains neutral with regard to jurisdictional claims in published maps and institutional affiliations. 